\title{
Futurology and mental health services: are we ready for the demographic transition?
}

\author{
Moira Connolly ${ }^{1}$
}

The Psychiatrist (2012), 36, 161-164, doi: 10.1192/pb.bp.111.034215

${ }^{1}$ Gartnavel Royal Hospital, Glasgow Correspondence to Moira Connolly (moira.connolly@ggc.scot.nhs.uk) First received 31 Jan 2011, final revision 13 Oct 2011, accepted 28 Nov 2011
Summary Planning for the future development of mental health services requires an understanding of the changing demographics of local populations. It is argued that the demographic transition faced by the UK requires mental health services to adopt an approach more typical of public health in responding to the needs of an increasingly ageing population.

Declaration of interest In July 2011 M.C. commenced a 2-year secondment to the Scottish Government as principal medical officer (mental health). The views in this article, however, are personal and have been developed over a time period preceding this appointment.
Systematically and imaginatively forecasting what might lie ahead based on present trends - futurology - is increasingly commonplace in the world of business, ${ }^{1}$ whereas making projections based on established statistics is a function of demography. ${ }^{2}$ All too often though, future thinking in health and social care is focused on immediate threats and consequences. The World Health Organization's European regional advisor for mental health writes:

We are living in significant and challenging times for mental health services across the world. On the one hand, many countries are in the middle of comprehensive reforms of their mental health systems, and these require funding. On the other, they are affected by the global financial crisis as regional and national economic recessions threaten to herald a social crisis in many countries. ${ }^{3}$

With a little more horizon scanning the concern that poses a major public and mental health challenge for the UK, in line with most European countries, is our increasingly ageing population. ${ }^{4}$ The potential impact for mental health service provision in relation to the preparedness of clinical staff has received scant attention in the medical literature, ${ }^{5}$ whereas the costs are certainly emerging as a concern among health economists. ${ }^{6}$ That all this is taking place in a world facing an ecological crisis characterised by climate change and the depletion of oil reserves, lends added impetus to the need to feel and be prepared. ${ }^{7}$

\section{The demographic transition}

Demographic transition describes the impact of births and deaths on the age distribution and size of a population over time. $^{2}$ It is most clearly illustrated with 'population pyramids' that describe the age structure of populations and can give an indication of previous population flows and likely future patterns. From the end of the 19th century the population structure of the UK along with that of most northern European countries changed, largely in response to falling birth and death rates (more so than migration) becoming more 'rectangular' in structure, as ongoing population ageing occurred from the apex of the pyramid rather than the base (as is the case in younger 'developing' countries). ${ }^{8}$

Using Scotland as an example we can see this process in action. According to the Registrar General's Annual Review for 2010, ${ }^{9}$ Scotland's population numbered 5222100 of which $17 \%$ were 16 years or less, $66 \%$ of working age and $17 \%$ of pensionable age (in 2008 they were a proportionately larger group than children). Between 1998 and 2008 there was a fall in the number of children of $9 \%$. At the same time, numbers of those over 75 rose by $13 \%$ and the $60-74$ age bracket rose by $10 \%$. Contributory factors include increasing life expectancy (seen since industrialisation) ${ }^{8}$ alongside reduced births, with the result that children born in 2009 have a life expectancy of 75.8 years for males and 80.3 years for females. Further projected changes for Scotland are illustrated in Fig. $1 .^{9}$

Such improved life expectancy is seen throughout the UK and remains a health outcome success story resulting from 'a multidisciplinary and intersectoral approach to the underlying causes of premature death and disability, ${ }^{10}$ but, allied with falling fertility rates it brings its own public health challenge.

\section{The challenge}

Are we ready to meet the challenge of our ageing population? ${ }^{11}$ Or should we indulge in 'apocalyptic demography' ${ }^{12}$ Some social scientists argue that it is demographic change that has a profound impact on the social, economic and political trends of a country rather than cause and effect operating the other way round. 


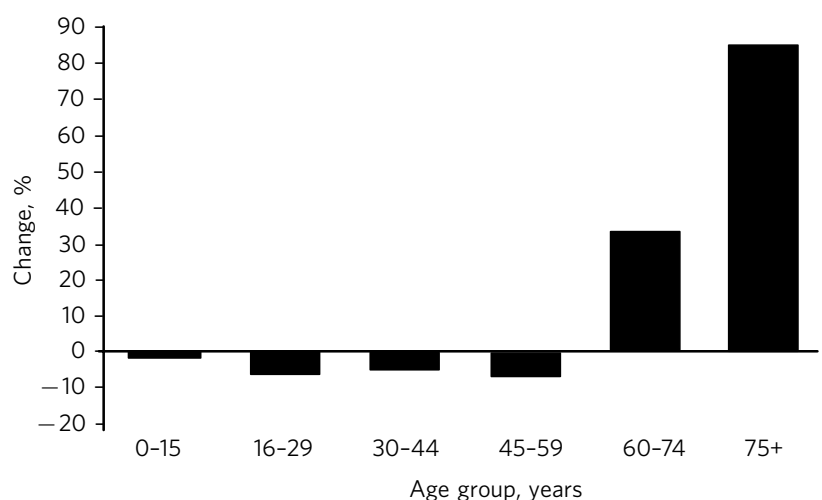

Fig 1 Projected percentage change in age structure of Scotland's population, 2008-2033 (based on 2008 projections). Adapted from Scotland's Population 2010 - The Registrar General's Review of Demographic Trends. ${ }^{9}$

Irrespective of social crises, it is likely that an 'epidemiological transition' will accompany this significant change in population make-up in that the burden of disease becomes increasingly dominated by chronic noncommunicable illness. The positive view is of a situation whereby 'compression of morbidity' prevails and the increasing years of life gained are lived disability free as morbidity rates fall more rapidly than mortality rates. ${ }^{13}$ With such a scenario there is the potential for ageing 'baby boomers' to contribute meaningfully and productively in society, their wisdom recognised, valued and utilised. Truly 'healthy' ageing.

Alternative propositions include a theory of balance whereby with increased life expectancy comes proportionate but predictable levels of disability-free years lived, the easier for healthcare and economic planning. A more pessimistic theory is that of 'chronic pandemy' ${ }^{13}$ accompanying an extension of morbidity scenario. It is this secular theory that appears to have captured media interest and concern. $^{12}$

We cannot risk simply pinning our hopes on morbidity compression. The potential changes of most relevance to mental health services if it is 'chronic pandemy' that emerges include more people with dementia, ${ }^{14}$ comorbid chronic physical illness and mental health problems ${ }^{15}$ and depression. ${ }^{16}$

And in a society where people increasingly live in single households $^{9}$ and are likely to experience reduced social capital with age, ${ }^{5}$ there will be more people in need of health and social care services.

\section{Garnering a response}

As suggested at the outset, demographic work allied with epidemiological skills will help health services and governments understand and predict the outcome of population shift. A broad focus on the role of health determinants seems the most promising route to minimising negative effects on quality of life and increasing the numbers of years lived disability free. Godfrey ${ }^{17}$ concludes that preventive strategies aimed at reducing or delaying the occurrence of illness or disabilities associated with normal ageing involve health, socioeconomic and environmental interventions, encouraging 'successful' ageing as outlined below.

\section{Sociocultural model of successful ageing}

Figure 2 depicts a sociocultural model of successful ageing. ${ }^{17}$ Such strategies must be rationale based and easily incorporated into usual practice, along with optimism that the pace at which individuals age physiologically can be modified and their contribution to age diversity in the community and workplace assured. ${ }^{11}$ Unfortunately, the wished for 'compression of morbidity' may not be experienced universally. From an in-depth analysis of the social determinants of health in older age, it appears that economic and health inequalities exist beyond working age, although the underlying reasons are not fully understood. ${ }^{19}$

\section{Dementia - prevention and early intervention}

Using dementia as an example, there is much that can be achieved to reduce individual morbidity, with evidencebased strategies for population-based interventions beginning to emerge. Although inconclusive thus far, more research has been called for on a number of drug treatment strategies aimed at disease modification, details of which are beyond the scope of this article. A public health-based review of policies for action at a population level targeting vascular risk factors concluded that in spite of individual gains, there was insufficient evidence to support populationbased approaches as a means of reducing dementia. ${ }^{20}$

Continued research on behaviours that may protect against the loss of physical and mental capabilities by focusing on individual behaviours has been recommended. Consideration has also been given to broader determinants of mental health, with genetics and ageing having an established role, but so too is a 'socially integrated lifestyle'

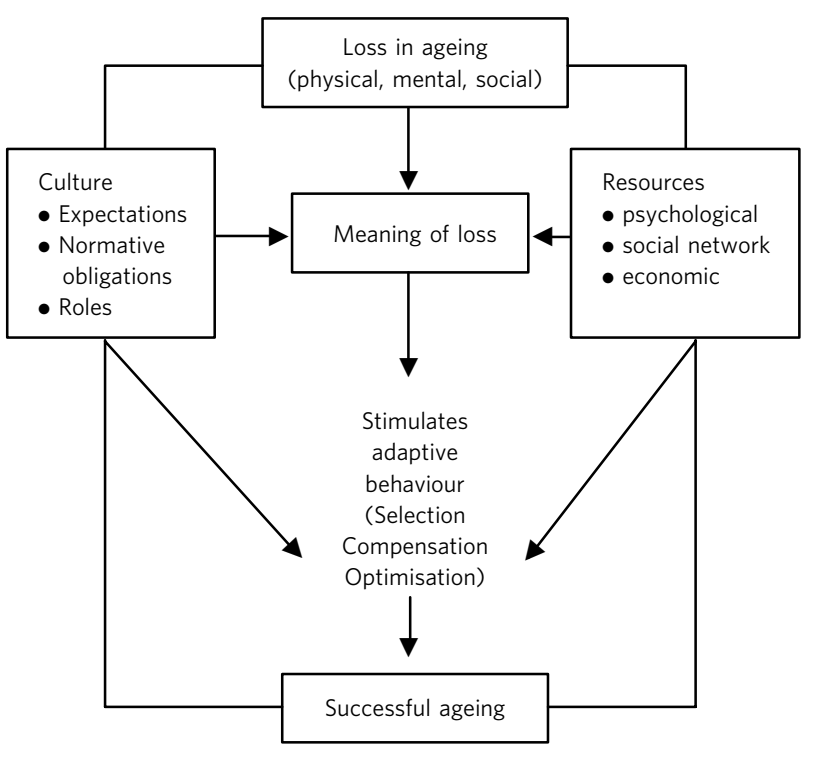

Fig 2 Sociocultural model of successful ageing. From Godfrey ${ }^{17}$ adapted with permission from Baltes \& Baltes. ${ }^{18}$ 
seen as a relevant 'long term multi-domain intervention' in dementia prevention. ${ }^{21}$

Interestingly, there are businesses prepared to invest in robots to act as 'cognitive companions' providing 'companionship and support' for people with failing memory. Is this an example of socioenvironmental support driven by consumerism? However, even with an increased focus on general health improvement, the predicted numbers are such that serious consideration needs to be given to who will provide treatment and care to increasing numbers of people with dementia. The implications for training and deployment of staff are such that an entire rethink of how services are provided is justified alongside a focus on what treatments are effective. Traditional age-determined boundaries will require realignment or review and, as with the challenge of providing healthcare to the ageing population as a whole, there is a need to pursue better coordination across health and social care. ${ }^{22}$

\section{Wider impacts}

As the early baby boomers reach retirement in 2012, what of the remaining workforce? How might they fare? As the cost to the economy of dementia trebles over the next 30 years, adults of working age may be contributing to the care of elderly relatives while competing in an increasingly globalised market with ensuing pressures on work-life balance. There is the potential for the economic downturn to differentially affect the most disadvantaged, as has happened with unemployment in the past. ${ }^{23}$ Unemployment places increased demands on mental health services, which in turn may experience a 'discouraged institution effect' whereby employment support is not provided for vulnerable groups such as people with mental health problems because of assumptions about lack of opportunities. The Royal College of Psychiatrists in its position statement on mental health and the economic downturn ${ }^{24}$ argues against this stance and advocates taking a 'long-term perspective' in order to achieve the best societal outcome, while acknowledging the likelihood of reduced funding and investment levels.

\section{Values and principles}

In facing up to this demographic shift, public health and mental health services should not shy away from that which is more 'public' than 'health'. In response to an article on the 'context' in family medicine, Watt neatly captures this when writing;

As populations get older, it is clear that the problems of looking after people cannot and should not be overprofessionalised. While services may be resource poor, communities are potentially people rich. In facing the challenges of ageing populations, professionals need to work in new ways with communities, reducing professional distance, while increasing partnership and accountability. In these ways, practitioners can be important social and economic determinants of health in the populations they serve. ${ }^{25}$

Unfortunately, a view still prevails within mental health that the value of building links between the public and mental health services is more easily said than done, ${ }^{26}$
The importance of equality and diversity, when offering services to elderly people, needs to be remembered if inequality and discrimination are to be avoided. Age Concern's 2007 report on improving services and support for older people with mental health problems ${ }^{16}$ rightly draws attention to Scotland's emphasis on mental health improvement and 'public mental health' (further developed in Towards a Mentally Flourishing Scotland ${ }^{27}$ ), with service developments aimed at being specifically inclusive of elderly people. This approach is echoed in the English No Health Without Mental Health: Delivering Better Mental Health Outcomes for People of all Ages, ${ }^{28}$ More recently though, mental health services have been described as 'among the most manifestly guilty of age discrimination within the National Health Service' and the case presented for professionals to respond to the Royal College of Psychiatrists' position statement on age discrimination in mental health ahead of impending age equality legislation. ${ }^{29}$ However, it remains worth emphasising the importance of focusing on the needs of all age groups in these developments, as today's younger people are the workers, caregivers and funders of tomorrow. We need to be assured of their resilience and self-esteem.

There is some evidence to suggest that today's young people do not have such a negative view of the older generations as the media portrays, choosing instead to recognise the value of intergenerational support. ${ }^{11}$ Paradoxically, psychotherapists working with elderly people have recorded a more negative outlook, ${ }^{5}$ although this may be skewed by them having proportionately more contact with those whose ageing is less 'successful'.

\section{Recommendations}

Drawing on the predicted demography for the UK's population (using Scottish figures as an example), aspects of the research base for general ageing and for dementia prevention, and some of the broad ranging public health and public mental health policies in place already, recommendations are perhaps best articulated in the style of a 360-degree feedback - when thinking of the future of mental health services, what should we do more of, less of and start doing?

We must engage more with our communities of interest if we are to respond successfully to the developing needs of our ageing population in a way that is economically and environmentally sustainable by tapping into the rich resource that is our multigenerational society. ${ }^{25}$ For clinicians this means even closer working with relatives and carers, with social work and primary care colleagues and other key clinical and voluntary support networks. For policy makers, more robust partnerships are essential, however drawn up or legislated for. By doing this we may go some way towards keeping future health and social care costs towards the lower end of what is currently predicted.

And given the financial forecast, there will need to be that bit more imagination applied by clinicians if we are to respond effectively to the mental health needs of our working-age - if not work-less - population. ${ }^{24}$

Research efforts should concentrate more on the community, focusing on treatments and models of care for 
which we have gaps in evidence of effectiveness. Unless we do so, we risk making poor decisions from a health economics perspective.

We must lessen the negative impact of discrimination on the grounds of age, otherwise we risk maintaining ageand gender-related inequalities. Close scrutiny of mental health services with a view to reducing inequalities of access to specialist interventions will shortly be driven by legislation - not just position statements - so there is a case to be made now for planners and clinicians to review the very basics of what services are delivered to whom and by whom. This is service redesign, but with demographic shift and age-related health inequalities among the drivers.

We must become involved in effective workforce planning now to ensure that as the baby boomers age, their valuable contributions to society are not lost to retirement, and focus on the health and well-being of our current and future workforce. With the future workforce in mind, given the increasing influence of activities and skills more usually associated with public health medicine than psychiatry, as we act as 'health advocates' and determine the direction of mental health strategy and service development, we should update our specialty curricula to ensure that current and future psychiatrists develop the competencies required to deliver 'public mental health'. With the support of the College this can be initiated within the curriculum review planned for this academic year and considered in future iterations of Good Psychiatric Practice. And as with effective appraisal, feedback and review on a regular basis is an essential component.

\section{Acknowledgement}

With thanks to Professor Phil Hanlon, Glasgow University, Department of Public Health, for his helpful comments on an initial draft.

\section{About the author}

Moira Connolly, MB Bch BAO, MRCGP, FRCPsych, is a consultant psychiatrist at Gartnavel Royal Hospital, Glasgow, UK.

\section{References}

1 Wikipedia. Future Studies. Wikipedia, no date (http//:wikipedia.org/ wiki/futurology). Accessed Feb 2012.

2 Grundy E. Demography and public health. In Oxford Textbook of Public Health, Fifth Edition, Vol. 2 (eds R Detels, R Beaglehole, MA Lansang, M Guildford): 734-51. Oxford University Press, 2009.

3 Muijen $M$. Challenging times for mental health services. Int Psychiatry 2010; 7: 1-2.

4 Kalache A. Ageing worldwide. In Epidemiology in Old Age (eds S Ebrahim, A Kalache): 22-31. BMJ Publishing, 1996.

5 Laidlaw K, Pachana NA. Aging, mental health, and demographic change: challenges for psychotherapists. Prof Psychol Res Pr 2009; 40: 601-8.

6 McCrone P, Dhanasiri S, Patel A, Knapp M, Lawton-Smith S. Paying the Price. King's Fund, 2008 (http://www.kingsfund.org.uk/publications/ paying_the_price.html).

7 Hanlon $\mathrm{P}$, Carlisle S. Do we face a third revolution in human history? If so, how will public health respond? J Public Health (Oxf) 2008; 30: 355-61.
8 Kinsella K. Demographic aspects. In Epidemiology in Old Age (eds S Ebrahim, A Kalache): 32-40. BMJ Publishing, 1996.

9 General Register Office for Scotland. Scotland's Population 2010 - The Registrar General's Review of Demographic Trends. Edinburgh, 2011 (http://www.gro-scotland.gov.uk/files2/stats/annual-review-2010/ j176746-00.htm).

10 Beaglehole R, Bonita R. Public health at the crossroads: which way forward? Lancet 2008; 351: 590-1.

11 Doyle $Y$, McKee M, Rechel B, Grundy E. Meeting the challenge of population ageing. BMJ 2009; 339: 892-4.

12 Martin R, Williams C, O'Neill D. Retrospective analysis of attitudes to ageing in the Economist: apocalyptic demography or opinion formers? BMJ 2009; 339: b4914.

13 Colvez A. Disability free life expectancy. In Epidemiology in Old Age (eds S Ebrahim, A Kalache): 41-8. BMJ Publishing, 1996.

14 Alzheimer's Society. Dementia UK 2007. Alzheimer's Society, 2007 (http://alzheimers.org.uk/site/scripts/download_info.php?downloadID $=1$ ).

15 The Future Vision Coalition. A Future Vision for Mental Health. The Future Vision Coalition, 2009 (http://www.newvisionformentalhealth.org.uk/ A_future_vision_for_mental_health.pdf)

16 Lee M. Improving Services and Support for Older People with Mental Health Problems. Age Concern. England, 2007.

17 Godfrey M. Prevention: developing a framework for conceptualizing and evaluating outcomes of preventive services for older people. Health Soc Care Community 2001; 9: 89-99.

18 Baltes PB, Baltes MM (eds). Psychological perspectives on successful ageing: the model with selective optimisation and compensation. In Successful Ageing: Perspectives from the Behavioural Sciences: 1-34. Cambridge University Press, 1990.

19 McMunn A, Breeze E, Goodman A, Nazroo J, Oldfield Z. Social determinants of health in older age. In Social Determinants of Health (2nd edn) (eds M Marmot, R Wilkinson): 267-96. Oxford University Press, 2006.

20 Stephan BC, Brayne C. Vascular factors and prevention of dementia. Int Rev Psychiatry 2008; 20: 344-56.

21 Fratiglioni L, Paillard-Borg S, Winblad B. An active and socially integrated lifestyle in late life might protect against dementia. Lancet Neurol 2004; 3: 343-53.

22 Fahy $N$, McKee $M$, Busse R, Grundy E. How to meet the challenge of ageing populations. BMJ 2011; 342: d3815.

23 Stafford B, Duffy D. Review of Evidence on the Impact of Economic Downturn on Disadvantaged Groups. Department for Work and Pensions Working Paper No 86. TSO (The Stationery Office), 2009.

24 Royal College of Psychiatrist, Mental Health Network, NHS Confederation, London School of Economics and Political Science. Mental Health and the Economic Downturn: National Priorities and NHS Solutions. Occasional Paper OP70. Royal College of Psychiatrist, NHS Confederation, LSE, 2009 (http://www.rcpsych.ac.uk/files/pdfversion/ OP70.pdf).

25 Watt G. Commentary on: what about the context in family medicine? Br J Gen Pract 2010; 60: 58.

26 Skuse D. Mental health services in primary care. Int Psychiatry 2010; 7: 3.

27 Scottish Government. Towards a Mentally Flourishing Scotland. Scottish Government, 2009 (http://www.scotland.gov.uk/Publications/2009/ 05/06154655/0).

28 HM Government. No Health Without Mental Health: Delivering Better Mental Health Outcomes for People of all Ages. Department of Health 2011 (http://www.dh.gov.uk/en/Publicationsandstatistics/Publications/ PublicationsPolicyAndGuidance/DH_123737).

29 Anderson D. Age discrimination in mental health services needs to be understood. Psychiatrist 2011; 35: 1-4. 